\title{
Anti-Black Prejudice as a Function of Exposure to the Negative Behavior of a Single Black Person
}

\author{
Eaaron I. Henderson-King \\ Loyola University Chicago
}

\author{
Richard E. Nisbett \\ University of Michigan
}

\begin{abstract}
The authors examined whether the negative behavior of 1 Black male would influence White participants' perceptions of Black Americans and behavior toward another Black person. In Study 1, it was found that participants in the Black-negative condition tended to stereotype Blacks more than participants in the Black-control condition did. It was also found that participants who had observed a negative behavior, whether it was performed by a Black or a White confederate, avoided a subsequently encountered Black person more often than did participants in either the positive condition or the control condition. In a 2nd study, interpersonal interactions with a Black person were minimized only after participants observed the negative behavior of a Black confederate. Study 3 extended the findings of Study 1 by showing that group level stereotypes and the expression of ingroup favoritism resulted from simply overhearing a conversation in which a Black person was alleged to have committed a crime.
\end{abstract}

A considerable amount of research has examined the circumstances under which contact between Whites and Blacks results in positive intergroup relations. Although much of this research has demonstrated that positive contact has beneficial outcomes for those in the contact setting, there is little evidence that such contact has prolonged effects or influences group level perceptions (see Stephan, 1985). Perhaps what is most disturbing, given the increased opportunity for interracial contact, is the considerable body of research that indicates that White Americans' attitudes toward Blacks remain, at best, ambivalent (Gaertner \& Dovidio, 1986; Katz \& Hass, 1988; Katz, Wackenhut, \& Hass, 1986; McConahay, 1982; Sears \& Kinder, 1985). One explanation for why it may be so difficult for contact to produce sustained effects is that a single Black person's behavior may have an inordinately large influence on White Americans' attitudes toward Blacks. These attitudes may be disproportionately affected when the Black person's behavior can be interpreted as negative. Thus, even in settings where positive intergroup contact is encouraged, simply encountering an individual Black person who performs a negative action, or a stereotype-relevant action, may reaffirm one's initial impressions of the larger group.

There are several theoretical reasons why observing the be-

Eaaron I. Henderson-King, Department of Psychology, Loyola University Chicago; Richard E. Nisbett, Department of Psychology, University of Michigan.

This article is based on a doctoral thesis submitted to the University of Michigan by Eaaron I. Henderson-King, who thanks the members of the dissertation committee: James Jackson, Melvin Manis, and Andre Modigliani. We also thank Donna Henderson-King, Galen Bodenhausen, Scott Tindale, and Kent Harber for their extremely helpful comments and suggestions on various drafts.

Correspondence concerning this article should be addressed to Eaaron I. Henderson-King, Department of Psychology, Loyola University Chicago, Chicago, Illinois 60626 . havior of a single Black person might result in more negative attitudes toward Blacks in general. Individual-to-group level generalization may be conceptualized as a process that results from the adherence to the "law of small numbers." Tversky and Kahneman (1971) have shown that people rely too heavily on small samples in making judgments and often fail to recognize that their observations can be attributed to sampling variability. Research by Nisbett and his colleagues (Borgida \& Nisbett, 1977; Hamill, Wilson, \& Nisbett, 1980; Nisbett \& Borgida, 1975 ) has shown that a variety of social judgments are dramatically affected by small, and sometimes manifestly atypical, samples of behavior. They have also shown that people have a strong tendency to ignore "base rate" information that is of greater relevance but is not as salient as a single instance (also see Rothbart, Fulero, Jensen, Howard, \& Birrell, 1978).

Research by Quattrone and Jones (1980) and Nisbett, Krantz, Jepson, and Kunda (1983) has served to clarify how the effects of relying on the law of small numbers can be amplified in intergroup relations. These researchers have shown that person-to-group generalization is more likely to result from an outgroup member's behavior. Others have found that direct negative interactions with dissimilar others will lead to the avoidance of subsequently encountered group members (Lewicki, 1985) and to a desire to minimize contact with outgroup members (Rosenfield, Greenberg, Folger, \& Borys, 1975). Quattrone and Jones suggested that person-to-group generalization occurs because people perceive outgroups as less variable and therefore see individual outgroup members as prototypic of the larger group.

In comparison, a perceiver who views the behavior of an ingroup member should rarely make individual-to-group generalizations. First, it has been shown that the negative behavior of an ingroup member is often attributed to situational rather than dispositional factors (Duncan, 1976). Second, even if the negative behavior of an ingroup member is attributed to dispositional factors, generalization should be minimized by the per- 
ception of ingroup heterogeneity (Linville, Salovey, \& Fischer, 1986; Nisbett et al., 1983; Quattrone \& Jones, 1980). Finally, one is usually unaware of one's group membership when in the presence of other ingroup members (McGuire, McGuire, Child, \& Fujioka, 1978); therefore, the negative or positive behavior of an ingroup member is less likely to be processed along group lines. Thus, a White perceiver's perceptions of Whites as a group should rarely be influenced by observing the actions of an individual White person.

The behavior of a single Black person may also influence group level perceptions because it is distinctive. In general, White Americans still have very little contact with Blacks (Judd, Park, Ryan, Brauer, \& Kraus, 1995). Because of this lack of contact, White perceivers may be more likely to view Blacks in a homogeneous manner (Feldman, Camburn, \& Gatti, 1986; Nelson \& Miller, 1995). Furthermore, a Black person's actions will be considerably more distinctive than those of a White person behaving similarly. Hamilton and his colleagues (Acorn, Hamilton, \& Sherman, 1988; Hamilton, Dugan, \& Trolier, 1985; Hamilton \& Gifford, 1976; McConnell, Sherman, \& Hamilton, 1994), as well as others (Meehan \& Janik, 1990; Spears, Van der Pligt, \& Eiser, 1985) have consistently shown how distinctiveness influences group level perceptions. Most relevant to the current research is the work conducted by Hamilton and Rose (1980) that indicated that stereotype maintenance occurs when the perceiver expects a relationship between two co-occurring variables. Hamilton and Rose (1980) paired stereotypic and counterstereotypic traits with different occupational groups. Although no correlation existed between the presented traits and the occupational categories, participants believed that the occupational groups were paired with their corresponding stereotypic traits more frequently than was actually the case. Such findings indicate that stereotypes are maintained because people process new information in line with preexisting stereotypes. The introduction of stereotyperelevant information should only serve to strengthen the perceived association between those traits associated with the observed behavior and the group.

In contrast, stereotype-irrelevant or -incongruent actions should have little influence on group level perceptions or behavior-in particular when the observed action is positive and is enacted by a person from a stigmatized outgroup. This asymmetry in the effects of stereotype-relevant and -irrelevant information might occur for a variety of reasons. First, once a negative impression of a group or an individual has been established, it is quite easy to confirm and very difficult to disconfirm it (Rothbart \& Park, 1986). Therefore, whereas witnessing a negative action may confirm one's original fears and expectations regarding an outgroup, a positive action may be overlooked, seen with suspicion, or attributed to some negative characteristic. Second, Weber and Crocker (1983) as well as others (Rothbart \& John, 1985; Rothbart \& Lewis, 1988; Smith \& Zárate, 1992) have argued that people subtype those group members who behave in a counterstereotypic fashion. Thus, due to cognitive processes that make such actions seem unrepresentative, positive actions by a member of a stigmatized group may have little influence on people's perceptions of the larger group.

Finally, research in the area of category priming shows that priming category exemplars will result in people using the category when both evaluating and behaving toward other category members (Higgins, Rholes, \& Jones, 1977; Rosenfield et al., 1975 ). Interactions with an outgroup member may also make group level stereotypes salient (Wilder, 1984), and stereotypecongruent behavior may strengthen the relationship between the social category and relevant category features (Smith \& Lerner, 1986; W. G. Stephan \& C. W. Stephan, 1993). Thus, observing or hearing about a Black person's negative behavior may make salient particular aspects of the group stereotype, result in stronger negative feelings toward Blacks, and increase the likelihood of avoiding a subsequently encountered Black person.

Although various researchers have shown that people will make individual-to-group generalizations (Hamill et al., 1980; Lewicki, 1985; Rosenfield et al., 1975), only Rosenfield et al. (1975) have examined whether the tendency of White Americans to avoid Blacks is influenced by the generalization process. In their study, Rosenfield et al. had a Black or a White confederate either panhandle White participants or ask them to contribute money to a worthy cause. Eventually, they were asked if they would be willing to volunteer some time to various campus organizations-one of which happened to be an African American group. Rosenfield et al. found that participants who were panhandled by a Black confederate were the least likely to voluntarily assist in a project coordinated by Blacks. Although this behavioral approach provides important information about one type of negative behavior and one outcome, it says little about the affective and cognitive aspects of the generalization process. Furthermore, very little research has examined whether individual-to-group generalization influences interpersonal interactions. The present research was an attempt to fill these theoretical gaps, to demonstrate the asymmetry in how White Americans perceive the negative and positive behaviors of a Black person, and to examine types of avoidance behaviors with obvious relevance to real-life intergroup contact situations.

\section{Study 1 Overview}

In Study 1, we examined whether the negative stereotype-related behavior of a Black person would make salient stereotypes associated with Blacks and result in the perceiver avoiding a subsequently encountered Black person. In this study, White participants observed either a Black or a White confederate act in either a negative, positive, or neutral manner. The participants were then taken to a room where they could sit next to either a Black person or a White person. The decision to sit next to either the White or the Black confederate was one dependent variable. Participants also assessed the relationship between Blacks and the concept hostile (a trait generally associated with Blacks). ${ }^{1}$

\footnotetext{
I The study was conducted over two semesters with a change in the secondary dependent measure occurring between the two semesters. In the first semester, participants completed a questionnaire concerning, among other things, their beliefs about Blacks. The questionnaire contained a series of perceived similarity measures and various symbolic racism items (Kinder \& Sears, 1981; McConahay \& Hough, 1976; Sears \& Allen, 1984; Sears \& McConahay, 1973). It was expected that the negative racial affect that might result from observing a negative action
} 
It was hypothesized that a Black confederate's negative behavior would result in increased levels of avoidance behavior and stereotyping. In comparison, neither the positive nor the neutral behavior of a Black confederate was expected to influence participants' behavior or perceptions.

\section{Method}

\section{Participants and Design}

Two-hundred-twenty-six students participated in the study over two semesters ( 49 male students and 32 female students in the first semester and 145 male students in the second semester) in partial fulfillment of a course requirement. In the second semester, during the debriefing, 8 of the 145 participants expressed some suspicion about the purpose of the study and were therefore not included in the data analyses. Also, 2 other participants' data on the stereotype salience measure were lost due to technical difficulties. The study was a 2 (race of confederate: Black vs. White) $\times 3$ (confederate's behavior: positive vs. control vs. negative) between-subjects design.

\section{Procedure}

After participants arrived in the waiting room, a White female experimenter entered and explained that the study they were about to participate in examined people's emotional reactions to news stories. The participants were also informed that they would complete a 5-min cognitive task for a second experimenter. This was an attempt to reduce any potential suspicion by dissociating the cognitive dependent measure from the rest of the study. The confederate (either Black or White) then entered the room, and the experimenter asked if he was Steve Tiernan.

In the negative condition, the interaction went as follows:

E(Experimenter): Hi, I just spoke with Jim, the guy whose session you came for, and he asked me to tell you that he will be down in a couple of minutes. Is that $0 . \mathrm{k}$ ?

C (Confederate): Yeah, but he'd better hurry (takes a seat).

At this point, the experimenter gave a consent form to the participant. After the participant completed the form (approximately $60 \mathrm{~s}$ ), the experimenter began the second interaction sequence.

E: (to participant): What you'll be doing today is reading various types of news stories and (the confederate interrupts)

C: (in a rude manner, while standing): Ive waited long enough.

E: But, you just got here.

C: He's late. I'm outta here (walks out of the waiting room).

The experimenter looked at the participant, shrugged, and then continued her briefing.

In the positive condition, the entire interaction between the experimenter and the confederate took place after the participant had been given the consent form.

E: Hi, I just spoke with Jim, the guy whose session you came for, and he asked me to tell you that he'll be about 25 minutes late. Is that o.k.?

C: I really can't. I have an important test coming up, so I really want to go to my class.

might influence participants' symbolic racism scores (Kinder \& Sears, 1981; Sears \& Allen, 1984). However, preliminary analyses of these data indicated there were no significant between-group differences, so these measures were dropped from the study.
E: Oh, you were his last person and he really needs to finish his study today.

C: Well, it's really inconvenient, but I guess I can get the notes from a friend in the class.

E: That's really nice. I'm sure he will be with you as soon as he can.

In the control condition, no interaction between the experimenter and the confederate occurred; the confederate simply walked into the waiting room and sat down.

In all conditions, as the experimenter brought the participant to the experimental room, she explained that there were two people still in the room from an eartier session. The room was $10 \mathrm{ft}$ by $20 \mathrm{ft}(3.0 \mathrm{~m} \times 6.1$ m) with four chairs in the middle of the room, spaced $6 \mathrm{in} .(15.2 \mathrm{~cm})$ from each another. A Black confederate and a White confederate were seated at opposite ends of the row of chairs. The confederates' positions were counterbalanced. The two confederates, who were unaware of the condition being run, faced the front of the room and continued to complete their questionnaires without looking up at the experimenter or the participant. Upon entering the room, the experimenter had the participant wait at the front of the room while she cleared material off two middle seats.

The experimenter then asked the participants to take two questionnaires, which were unrelated to the study, of a table that was equidistant from the two available chairs and to then take a seat. The experimenter then noted where the participants sat. ${ }^{2}$ The confederate seated closest to the participant waited approximately $45 \mathrm{~s}$ before leaving; the second confederate followed $45 \mathrm{~s}$ later. After completing the questionnaires, the participants were informed that the next phase of the session would entail them completing the brief "cognitive task" (the semantic differential task) mentioned earlier.

\section{Assessment of Perceived Hostility}

In the next phase of the study, the participants were informed that they would be completing a study that examined people's conceptions of their social environment. In completing the task, the participants were presented with a word pair consisting of a group and a trait (e.g. young-athletic, Blacks-hostike, Whites-helpful). Participants were first asked to assess the extent to which American society believed the group and the trait were associated. They were then asked to assess how they viewed the relationship between the group and the trait. Ratings were made on a 9-point scale ranging from 1 (not at all related) to 9 (extremely related). This task was similar to the lexical decision task various researchers have used to measure the strength of association between two words (Dovidio, Evans, \& Tyler, 1986; Dovidio \& Gaertner, 1981, 1983; Gaertner \& Mcl aughlin, 1983). Here, however, associated strength was directly, rather than implicitly, assessed.

Past research has shown that White Americans view Blacks as being poor, rhythmic, hostile, lazy, and athletic (Devine, 1989; Dovidio et al., 1986; Gaertner \& McLaughlin, 1983; Weitz \& Gordon, 1993). As part of our study, a preliminary survey of 43 undergraduates provided further evidence of a Blacks as hostile stereotype; respondents indicated that American society sees hostile as strongly associated with Blacks. In the current study, 4 of the 20 word pairs were of primary interest: Blacks-hostile, Blacks-helpful, Whites-hostile, and Whites-helpful.

Sanyo computers were used to present the 20 semantic differential word pairs. In completing the task, participants were presented with one of the following arientation words: you or society. The instructions

\footnotetext{
${ }^{2}$ Previous research has found that seating preference is a valid unobtrusive measure of racial attitudes (Campbell, Kruskal, \& Wallace, 1966; Macrae et al., 1994). For example, Campbell et al. (1966) found that Black and White students were more likely to sit adjacent to one another at a liberal as opposed to a conservative university.
} 
stated that if the word you appeared, the participants should rate how related they thought the two following words were. If society appeared they should rate how society viewed the word pair. Both the orientation word and the word pair that followed were presented for $1 \mathrm{~s}$. After the word pair was presented, the rating scale appeared for $1 \mathrm{~s}$, and the screen was then cleared. Participants then rated the relatedness of the word pair by pressing one of the keys marked one through nine. For all participants, ratings for society were always made before the self-ratings, and the word pairs were randomly presented. Because the society ratings would most likely be more extreme than the self-ratings, we felt that having participants complete the society ratings before the self-ratings would result in their feeling more comfortable expressing their own beliefs. After completing the semantic differential task, participants were debriefed.

Although during the verbal debriefing participants said that they felt that the negative and positive behaviors were indeed negative and positive, no measures of how they viewed the behaviors were taken. Furthermore, we did not know whether participants perceived the Black and the White confederates' behaviors in the same fashion. In an attempt to address these problems, we conducted an additional study in which the positive and negative behaviors were reenacted. The interaction between the confederate and the experimenter was videotaped and shown to 107 White undergraduates. The study was a 2 (race of confederate) $\times 2$ (confederate's behavior) between-groups design, with the dependent variables being the participants' ratings of the confederate's behavior on five adjectives (positive, friendly, helpful, negative, and hostile). The ratings were made on a 7-point scale ranging from 1 (not at all) to 7 (very). The positive adjectives and the negative adjectives were then used to create a positive index and a negative index.

We conducted a 2 (behavior) $\times 2$ (confederate's race) multivariate analysis of variance (MANOVA), with the positive and negative indexes as dependent measures. As expected, there was only a significant multivariate main effect for behavior, $F(2,102)=144.55, p<.001$. Univariate analyses indicated that participants in the positive condition viewed the confederate's behavior as more positive $(M=5.02)$ than did participants in the negative condition $(M=1.66), F(1,103)=274.96, p<$ .001 . In comparison, those in the negative condition rated the confederate's behavior as significantly more negative $(M=5.92)$ than did participants in the positive condition $(M=3.25), F(1,103)=162.67, p<$ .001 . The results indicate that participants did not differentially perceive the behavior of the Black and White confederates.

\section{Results}

Participants' behavioral decisions regarding whom to sit beside as a function of the confederate's race and behavior are presented in Table 1. It may be noted first that there was a slight tendency for participants to be more likely to sit next to the

Table 1

Percentage Sitting Next to a Black Confederate as a Function of the Race and Behavior of the First Confederate

\begin{tabular}{cccc}
\hline & \multicolumn{3}{c}{ Behavior of confederate } \\
\cline { 2 - 4 } Race of confederate & Positive & Control & Negative \\
\hline Black & $56 \%$ & $56 \%$ & $30 \%$ \\
$n$ & 36 & 36 & 37 \\
White & $63 \%$ & $64 \%$ & $46 \%$ \\
$n$ & 38 & 36 & 35 \\
\hline
\end{tabular}

Note. $N=218$.
Black confederate rather than the White confederate. We suspect this occurred because White Americans have become increasingly averse to expressing negative attitudes toward Blacks or exhibiting negative behaviors toward them (Crosby, Bromley, \& Saxe, 1980; Fazio, Jackson, Dunton, \& Williams, 1995; Judd et al., 1995).

A 2 ( race of confederate) $\times 3$ (behavior) $\times 2$ ( sex of subject) analysis of variance (ANOVA) was conducted on participants' seating choices. ${ }^{3}$ The analysis revealed a significant main effect for behavior, $F(2,212)=4.74, p<.01$. Newman-Keuls analyses revealed that the main effect was a result of participants in the negative condition avoiding a subsequently encountered Black more often than participants in either the positive condition $(p<.06)$ or the control condition $(p<.06)$.

Contrary to our predictions, the Race $\times$ Behavior interaction was nonsignificant, $F(2,212)=0.24, n s$. Planned comparison analyses were then conducted to determine whether participants in the Black-negative condition were significantly less likely to sit near a Black person than participants in the Blackpositive or Black-control conditions. The analyses revealed that participants in the Black-negative condition tended to avoid a subsequently encountered Black person more frequently than did participants in either the Black-positive condition, $F(1$, $212)=3.62, p<.05$ or the Black-control condition, $F(1,212)$ $=3.62, p<.05$. Although the difference between the Blacknegative and the White-negative conditions was in the expected direction, it was not statistically significant, $F(1,212)=2.55$, $p<.11$. Although the behavior of participants in the Whitenegative condition differed from that of participants in the White-positive and White-control conditions, Newman-Keuls analyses indicated that the differences were not statistically significant.

To examine whether the Black confederate's behavior in the negative condition made salient the stereotype of Blacks as hostile, we performed a 2 (Race) $\times 3$ (Behavior) $\times 2$ (Rating: Self vs. Society) $\times 2$ (Target Group: Blacks vs. Whites) mixed factors ANOVA, with Ratings and Target Group treated as repeated measures factors. Table 2 presents the mean ratings for hostility for Blacks and Whites as a function of the confederate's race and behavior. The analysis revealed a significant main effect for Target Group, $F(1,123)=53.41, p<.00001$, with participants perceiving Blacks as more hostile, $M=4.70$ than Whites, $M=3.76$. There was also a main effect for Rating, $F(1$, $123)=34.88, p<.00001$, with Self Ratings, $M=3.81$ being lower than Society Ratings, $M=4.65$.

The main effect for target group was qualified by a significant Race $\times$ Behavior $\times$ Target Group interaction, $F(2,129)=3.35$, $p<.05$. As hypothesized, a significant Behavior $\times$ Target Group simple interaction was found in the Black confederate condition, $F(2,65)=4.40, p<.02$. Planned comparison analyses

\footnotetext{
${ }^{3}$ A 2 ( race of confederate) $\times 3$ (behavior) $\times 2$ (seating choice) $\times 2$ (sex of participant) Hierarchical Loglinear analysis was also conducted. As with the ANOVA, there was a significant main effect for behavior, with participants in the negative condition avoiding the subsequently encountered Black more often than participants in the positive and control conditions, partial $\chi^{2}(2, N=218)=7.56, p<.05$. The Race $X$ Behavior interaction was nonsignificant, partial $\chi^{2}(2, N=218)=1.35$, ns.
} 
Table 2

Mean Ratings of Blacks and Whites as Hostile as a Function of the First Confederate's Race and Behavior

\begin{tabular}{lccc}
\hline & \multicolumn{3}{c}{ Behavior of confederate } \\
\cline { 2 - 4 } $\begin{array}{c}\text { Race of } \\
\text { confederate }\end{array}$ & Positive & Control & Negative \\
\hline Black & & & \\
$\quad$ Blacks-hostile & 4.73 & 4.12 & 5.46 \\
$\quad$ Whites-hostile & 3.56 & 4.07 & 3.89 \\
White & & & \\
Blacks-hostile & 4.90 & 4.73 & 4.56 \\
Whites-hostile & 4.08 & 3.39 & 3.57 \\
\hline
\end{tabular}

Note. Higher values indicate a stronger perceived relationship between the group and the trait.

revealed that participants in the Black-negative condition perceived Blacks as more hostile than did participants in the Black-control conditions, $F(1,65)=12.49, p<.001$. In comparison, participants' ratings for hostility of Whites were unaffected by a Black confederate's behavior, $F(2,65)=1.14, n s$. The Behavior $\times$ Target Group simple interaction analysis in the White confederate condition was nonsignificant $(F<1)$. As expected, observing a Black person's negative actions resulted in participants perceiving Black Americans as hostile. In contrast, comparable behavior by a White person had little influence on White participants' perceptions of White Americans.

\section{Discussion}

The aim of Study 1 was to examine how observing the positive or negative actions of an individual Black person would affect White participants' behavior toward a subsequently encountered Black person and White participants' perceptions of Blacks as a group. The results of Study 1 provided partial support for the hypothesis that observing the negative behavior of a Black person would result in avoidance behavior and the perception of Blacks as hostile. Witnessing the hostile behavior of either a Black or a White confederate resulted in participants avoiding a subsequently encountered Black person. Additional analyses, however, revealed significant effects of type of behavior in only the Black confederate condition. Participants who saw the Black negative behavior were more likely later to avoid a Black person than were those who saw either the neutral or the positive behavior of a Black confederate. Although viewing the negative behavior of a White confederate led to avoidance of a Black person, the differences between the White-negative and the White-positive and control conditions were nonsignificant. Furthermore, only a Black confederate's negative behavior had an adverse effect on participants' perceptions of Blacks; those participants who were exposed to a Black confederate's negative behavior were more likely to adhere to the stereotype of Blacks as hostile.

The finding that participants in the White-negative condition exhibited avoidance behavior was unexpected. It may be, however, that seeing the negative encounter had two effects. First, in the Black-negative condition, the behavior made salient group level stereotypes and initiated individual-to-group level pro- cesses. Such a process would account for both the cognitive and behavioral findings in the Black-negative condition. Second, observing the negative encounter may have also created a momentary increase in arousal or anxiety. Normally, participants come to an experiment expecting a fairly mundane, and maybe even boring, experience. So it could be somewhat arousing to see a moderately unpleasant interaction taking place. This increase in arousal may have led participants to avoid a dissimilar other, or desire to be near a similar other, to feel more comfortable (Clark \& Isen, 1982; Schachter, 1959). Because participants in the first study were making a very instantaneous decision regarding whom to sit near, an increase in arousal or being unsettled might have been just enough to influence such a decision. In a second study, we examined whether a more involved and elaborated interaction would be affected by observing a Black confederate's negative behavior.

\section{Study 2}

In Study 2, participants interviewed a Black person after either observing the negative actions of a Black or a White confederate or not observing any action by a confederate. Participants were told that they would interview someone (a Black male student) for a position as a dormitory resident and that the interview could last up to $20 \mathrm{~min}$. If, as we suspected, participants in the White-negative condition were initially unsettled by the negative interaction, this arousal should have quickly dissipated as long as nothing occurred during the interaction that accentuated or maintained such feelings. In contrast, because observing a Black person's negative behavior primes group level stereotypes and initiates individual-to-group generalization, we should have found that observing a Black confederate's negative behavior would result in minimizing contact with a second Black person.

\section{Method}

\section{Participants and Design}

Participants were 129 White undergraduates, 93 men and 36 women, from an introductory psychology course. Sixty-seven students participated in the first semester, whereas 62 completed the study in the second semester. The experiment was a one-way between-groups design, for which interaction length was the dependent variable.

\section{Procedure}

On entering the waiting room, participants were asked by an experimenter (E2) whether they were present for Jim's study. E2 left the room after the participants stated that they were present for a different study. Each session included a Black man who would be interviewed, a White participant who would conduct the interview, and a White male confederate who supposedly would be observing the interaction. The "observer" was included in the session in an attempt to minimize participants' suspicion regarding being selected as either the interviewer or the interviewee, because from their perspective another "participant" could have selected their role. E2 then reentered the waiting room with the participant's experimenter (E1) explaining that she would have to cancel her session because one of her participants had not yet arrived. After a brief conversation between the two experimenters, El informed the group that the study they were about to participate in examined whether certain interviewing techniques were better than others. The group was 
informed that they would be participating in an interview and that one person would be chosen as the interviewer, one the interviewee, and one as the observer of the interaction. The experimenter then explained that further instructions would be given to each person after the roles were determined.

The experimenter then let each person select a number from a box. Regardless of which number was chosen, the White participant was always given the role of the interviewer, the Black male student was the interviewee, and the White confederate was the observer. After each role had been determined, the experimenter took the Black interviewee and the White confederate out of the waiting room.

Negative conditions. In the negative conditions, the interaction between the male confederate and the experimenter was similar to that in Study 1 . In brief, E2 reentered the waiting room after the male confederate, who was either Black or White, arrived. After asking the confederate his name, she politely asked him if he could reschedule because his session had been canceled due to his tardiness. The confederate became outraged and, after a brief interaction, stormed out of the waiting room.

Control condition. In the control condition, E2 entered the waiting room, glanced around, and then left.

After approximately $1 \mathrm{~min}, \mathrm{El}$ reentered the waiting room and informed the participants that they would be conducting an interview for a dormitory resident assistant position (RA) and that the interview could last up to $20 \mathrm{~min}$. The experimenter explained that because most people had lived in the dormitories for at least a year, they were familiar with the tasks of an RA, and that the topic would therefore be of some relevance to them. In conducting the interview, the participants could ask questions from a list of 31 items or make up their own questions. After completing the interview, the participants were fully debriefed.

The study was conducted over two semesters. In the first semester, Black confederates were used as interviewees, whereas in the second semester naive Black participants were the interviewees. The procedure and methodology were the same for both semesters, except that only male students were used in the second semester. Also, the naive participants were informed that they would be asked to take on the role of a student interviewing for an RA position. ${ }^{4}$

\section{Results and Discussion}

If the negative stereotype-congruent behavior of the Black confederate resulted in participants minimizing contact with another Black, then we should have found shorter interviews being conducted in the Black-negative condition. The 3 (condition) $\times 2$ (interviewee: naive vs. confederate) ANOVA revealed significant main effects for interviewee, $F(1,123)=$ $6.64, p<.02$, and condition, $F(2,123)=4.29, p<.02$. The main effect for interviewee was a result of interactions being significantly longer when participants interacted with a naive Black subject ( $M=635.3 \mathrm{~s}$ ) than with a Black confederate ( $M$ $=517.3 \mathrm{~s}$ ). As expected, Newman-Keuls analyses revealed that the main effect for condition was a result of participants in the Black-negative condition conducting shorter interviews, $M=$ $478.1 \mathrm{~s}$, than did participants in either the control condition, $M$ $=620.9 \mathrm{~s}$, or the White-negative condition, $M=623.2 \mathrm{~s}$, $(p \mathrm{~s}<$ $.05)$. Equally important, the results clearly indicate a lack of difference between the White-negative and the control conditions. There was also no significant Condition $\times$ Interviewee interaction $(F<1)$.

These results indicate that participants attempted to minimize contact with a Black person after observing a Black confederate's negative actions. We also found that participants in the White-negative condition interacted with the Black inter- viewee for the same amount of time as participants in the control condition did. Thus, in the White-negative condition, it seems as though any increase in the desire to minimize contact with a Black person was most likely due to a momentary increase in arousal.

\section{Study 3}

In Study 1 and in Study 2, we focused on how observing the negative behavior of a Black person affects both people's perceptions of Blacks and their behavior toward a second Black person. Study 3 was designed to examine whether the individual-to-group generalization process has implications beyond stereotype priming and the avoidance of individual outgroup members. In Study 3, we focused on participants' feelings and attitudes toward Blacks. We also examined whether beliefs about how much power Blacks and Whites have in society are influenced by a Black individual's negative actions. Previous research has shown that ingroup orientation increases as the relative difference in power shifts in favor of an outgroup (Gurin \& Townsend, 1986). Thus, if the negative behavior of a Black person results in increased ingroup orientation, we should expect to find a smaller difference in how much power participants believe Whites and Blacks hold in American society.

We also attempted to redress a problem with the semantic differential task in Study 1. In Study 1, by repeatedly exposing participants to the word Blacks, we may have activated stereotypes that participants held of Blacks. Several researchers have shown that exposing people to a category member serves to make various elements of the category salient. The fact that participants in every condition except the Black-control perceived Blacks as significantly more hostile than Whites supports such a contention. In Study 3, we attempted to deal with this problem by pairing the word Blacks with only a single trait term.

Furthermore, in this study we examined whether simply hearing about the negative action of an outgroup member could affect people's feelings and attitudes toward the outgroup. Participants in the study overheard one end of a conversation in which a confederate informed a friend that a mutual acquaintance had been assaulted by either a Black man or a White man. After the conversation, participants assessed their feelings and beliefs regarding Blacks and Whites. It was expected that participants in the Black assailant condition would perceive Blacks as more antagonistic than would participants in either the White assailant or control conditions. We also believed those participants in the Black assailant condition would feel less positive toward Blacks and view Blacks as having more power in society relative to Whites. In comparison, hearing about a White assailant's behavior was not expected to affect participants' feelings and beliefs.

\footnotetext{
${ }^{4}$ The change from confederate interviewees to real interviewees was dictated by our interest in determining whether our preliminary findings would be observed in a more naturalized setting. It should be noted that such a change was more likely to decrease the chance of finding significant effects because the use of naive participants as interviewees has the potential of increasing the between-group variance.
} 


\section{Method}

\section{Participants and Confederates}

Participants were 77 (44 female and 33 male) undergraduates from Loyola University Chicago who participated in the study as partial fulfillment of a course requirement. Five of the participants ( 2 in the Black assailant condition and 3 in the White assailant condition) were excluded from the analyses because their session included a Black participant. Preliminary analyses indicated that these participants tended to express more positive attitudes and perceptions toward Blacks than those whose sessions did not include Black participants. Five confederates ( 3 women and 2 men) took part in the study.

\section{Dependent Variables}

Perceived antagonism. Participants assessed the extent to which the trait antagonistic was related to both Blacks and Whites on a 9-point scale ranging from 1 (unrelated) to 9 (related).

Racial affect. Nacoste-Barnes, Holt, Fender, and Lennon's (1993) measure of racial affect was used to assess participants' feelings about Blacks and Whites. ${ }^{5}$ Participants evaluated their positive feelings about each group on a 9-point scale that ranged from 1 (no positive feelings) to 9 (many positive feelings). They also completed parallel items for their negative feelings. Nacoste-Barnes et al. found that positive and negative feelings toward Blacks were negatively correlated, $r=-.62$. Furthermore, they found that both measures were strongly correlated with the Modern Racism Scale (positive, $r=-.58$; negative, $r=.59$ ) and Old-Fashioned Racism Scale (positive, $r=-.56$; negative, $r=.49$ ).

Power discontent. We used the National Election Study's power discontent measure to assess participants' attitudes toward Blacks and Whites (Gurin, 1985; Gurin \& Townsend, 1986; Kalmuss, Gurin, \& Townsend, 1981). In completing the items, participants were asked to rate both groups in terms of how much influence each group had in American society. Scores could range from -2 (far too little power) to 2 (far too much power), with 0 denoting $j$ ust enough power. Participants also rated older adults, gay men and lesbians, Hispanics, feminists, men, liberals, women, and conservatives.

\section{Procedure}

Students participated either individually or in pairs. On arriving for the session, participants sat on a long bench situated outside the laboratory area and across from a set of escalators. After all of the participants arrived, the experimenter told them that she or he was waiting for a few more people and that if they did not arrive in a few minutes the session would begin. The experimenter signaled to a waiting confederate who then proceeded up the escalator to the waiting participants. While on the escalator, the confederate began talking into a cellular phone. After sitting approximately $5 \mathrm{ft}$. $(1.5 \mathrm{~m})$ away from the participants, the confederate informed the person that a mutual female friend had been assaulted and robbed. The friend's resultant injuries included stitches below her right eye and a swollen lip. In discussing the incident, the confederate noted that the victim could only tell that the assailant was White (or Black) and looked as though he might have been a student. In the control condition, the confederate told the person that the friend had slipped on a patch of ice and fallen, resulting in the same injuries as described above.

To determine whether the conversation was loud enough for participants to hear, the experimenter listened from a hidden position. The position was just beyond the participants, which meant that the experimenter was farther away from the confederate than the participants were.

The experimenter waited for approximately $1 \mathrm{~min}$ before coming out and asking the confederate if he or she was present for the experiment.
After it was determined that the confederate was present for a different experiment, the experimenter brought the participants to the laboratory. The participants were informed that the study in which they were participating examined the impression formation process and would only take about $5 \mathrm{~min}$. The experimenter then explained that due to the brief nature of the study, they would also complete a questionnaire for another researcher.

After completing the impression formation task, the participants were given the questionnaire and informed that the study examined people's feelings and beliefs about various issues and groups in American society. Included in the questionnaire were the racial affect, power discontent, and semantic differential measures. After completing the questionnaire, participants were asked whether they heard the confederate's conversation and what they thought the study examined. They were then debriefed.

\section{Results and Discussion}

Preliminary analyses revealed no effects of Confederate, so this factor was eliminated from the analyses.

\section{Manipulation Check}

It is interesting that only $21(29 \%)$ of the 72 participants reported overhearing the conversation. Such a finding could be problematic if it were indeed the case that more than $70 \%$ of the participants failed to hear or pay attention to the conversation. If this had been the case, however, we would have found that perceptions of Blacks did not vary as a function of condition for those claiming not to have heard the conversation. In comparison, those who reported hearing the conversation should have perceived Blacks as more antagonistic in the Black assailant condition. A 3 (Black assailant vs. White assailant vs. accident control) $\times 2$ (heard vs. not heard) ANOVA was conducted, with the antagonistic rating for Blacks as the dependent variable. The analysis revealed a main effect for hearing, $F(1,64)=13.27, p$ $<.001$. Participants who claimed not to have heard the conversation actually perceived Blacks as more antagonistic, $M=$ 4.52, than did participants who stated that they heard the conversation, $M=2.91$. There was also a significant main effect for conversation, $F(1,64)=8.34, p<.001$, with participants in the Black assailant condition perceiving Blacks as more antagonistic, $M=5.04$, than did participants in either the White assailant, $M=4.00$, or the accident control condition, $M=3.08$. Most important, there was no significant Conversation $\times$ Hearing interaction, $F<1$. These findings suggest that participants who claimed not to have heard the conversation either felt uncomfortable telling us that they were listening to another per-

\footnotetext{
${ }^{5}$ Although this measure of racial affect has not been validated, for our purposes it had a number of advantages over established measures of racial attitudes. First, because we were primarily interested in participants' negative and positive feelings about Blacks and Whites, we wanted a measure that would directly assess these aspects of racial attitudes. In contrast, the Modern Racism, Traditional Racism, Symbolic Racism, and Racial Ambivalence scales measure more general racial attitudes. Second, because the measure is relatively short, we believed that it would be less likely to raise participants' suspicions regarding the study's purpose. Third, it allowed us to compare participants' feelings about Blacks with their feelings about Whites, a comparison that is not possible with the above mentioned measures of racism.
} 
Table 3

Mean Antagonism Ratings for Blacks and Whites as a Function of Conversation

\begin{tabular}{cccc}
\hline & \multicolumn{3}{c}{ Conversation } \\
\cline { 2 - 4 } Trait & Black assailant & White assailant & Accident \\
\hline Blacks' antagonism & $5.04_{\mathrm{a}}$ & $4.00_{\mathrm{b}}$ & $3.08_{\mathrm{b}}$ \\
Whites' antagonism & $4.16_{\mathrm{b}}$ & $4.71_{\mathrm{b}}$ & $4.16_{\mathrm{b}}$ \\
\hline
\end{tabular}

Note. Higher values indicate a stronger perceived relationship between the group and the trait. Across rows, means with differing subscripts are significantly different at or below $p<.05$.

son's conversation or attempted to suppress the fact that they were overhearing the interaction.

\section{Perceived Antagonism}

A 3 (Conversation) $\times 2$ (Sex) $\times 2$ (Rating: Blacks vs. Whites) mixed factor ANOVA was conducted with conversation and sex as between-subjects factors and Antagonistic Ratings treated as a repeated measures factor. The analysis revealed a significant Conversation $\times$ Rating interaction, $F(2,64)=$ $5.52, p<.007$. Simple effects analyses revealed that participants' perceptions of Blacks as antagonistic varied as a function of condition, $F(2,64)=7.12, p<.005$ ( see Table 3). NewmanKeuls analyses revealed that those in the Black assailant condition perceived Blacks to be significantly more antagonistic than did those in the White assailant condition, $p<.05$, and in the accident control condition, $p<.05$. In contrast, participants' perceptions of Whites' antagonism were unaffected by the conversations, $F(2,64)=1.72, n s$. Participants in the Black assailant condition also perceived Blacks as somewhat more antagonistic than Whites, $F(1,64)=3.23, p<.10$. In comparison, those in the accident condition perceived Blacks as less antagonistic than Whites, $F(1,64)=5.05, p<.05$.

Thus, simply overhearing a conversation in which a Black individual is the perpetrator of a hostile event resulted in participants perceiving Blacks as antagonistic. In comparison, the same behavior by a White person had little effect on participants' perception of Whites as antagonistic.

\section{Racial Affect}

To examine feelings toward Blacks and Whites, we created an affect score by subtracting participants' negative feeling scores from their positive feeling scores. Resulting scores could range from 8 to -8 , with positive scores indicating more positive feelings and negative scores indicating more negative feelings. We conducted a $3 \times 2 \times 2$ (Affect: Blacks vs. Whites) mixed factors ANOVA using participants' Affect toward Blacks and Whites as a repeated measures factor. The analysis revealed a significant main effect for Affect, $F(1,65)=6.15, p<.02$, with participants expressing more positive feelings toward Whites $(M=$ $3.14)$ than Blacks $(M=2.20)$. The main effect for Affect was qualified by a significant Conversation $\times$ Affect interaction,
Table 4

Mean Feelings for Blacks and Whites as a

Function of Conversation

\begin{tabular}{lccc}
\hline & \multicolumn{3}{c}{ Conversation } \\
\cline { 2 - 4 } Trait & Black assailant & White assailant & Accident \\
\hline Black feelings & $1.69_{\mathrm{a}}$ & $3.38_{\mathrm{b}}$ & $1.92_{\mathrm{a}}$ \\
White feelings & $3.96_{\mathrm{a}}$ & $3.24_{\mathrm{a}}$ & $2.12_{\mathrm{b}}$ \\
\hline
\end{tabular}

Note. Higher values indicate more positive feelings. Across rows, means with differing subscripts are significantly different at or below $p<.05$.

$F(2,65)=5.16, p<.01$. As shown in Table 4, simple effects analyses revealed that participants in the Black assailant condition expressed more positive feelings toward Whites than toward Blacks, $F(1,65)=9.48, p<.001$. In comparison, those in the White assailant and control conditions reported feeling equally positive toward Blacks and Whites. As can be seen in Table 4, the difference in participants' feelings toward Blacks and Whites in the Black assailant condition was a result of participants coming to express more positive feelings toward Whites rather than expressing more negative feelings toward Blacks.

\section{Power Discontent}

If the negative behavior of a Black person changed participants' perceptions of the influence Blacks and Whites have in society, we should have found smaller power differentials in the Black assailant condition than in the White assailant or the accident conditions.

It can be seen in Table 5 that participants in all conditions believed that Whites have more power than Blacks. However, this belief was substantially muted in the Black assailant condition. We conducted 3 (Conversation) $\times 2$ (Sex of subject) $\times 2$ (Power Discontent: Blacks vs. Whites) mixed factors ANOVA using participants' Power Discontent scores for Blacks and Whites as a repeated measures factor. The analysis revealed a significant Conversation $\times$ Power interaction, $F(2,63)=3.91$, $p=.025$. As can be seen in Table 5 , the smaller power differential between Blacks and Whites was a result of participants in the Black assailant condition feeling as though Whites had significantly less power in society than did participants in the

Table 5

Mean Power Discontent Ratings for Blacks and Whites as a Function of Conversation

\begin{tabular}{cccr}
\hline & \multicolumn{3}{c}{ Conversation } \\
\cline { 2 - 4 } Trait & Black assailant & White assailant & Accident \\
\hline Blacks-power & -0.16 & -0.52 & -0.54 \\
Whites-power & 0.64 & 1.33 & 1.04 \\
\hline
\end{tabular}

Note. Higher values indicate greater perceived influence. 
White assailant and the accident conditions, $F(1,63)=4.96, p$ $<.05$,

In summary, these findings reaffirm our contention that merely hearing about a negative event that involves a single Black person will make salient Whites' perceptions of Blacks as antagonistic or hostile. The results also indicate that such events increase ingroup favoritism, rather than outgroup derogation, and produce a belief that Whites have too little power relative to Blacks in society. These latter findings are consistent with previous research that showed that intergroup bias is often manifested by pro-ingroup as opposed to anti-outgroup sentiments (Brewer, 1979; Gaertner \& Dovidio, 1986). There are no comparable consequences of exposure to the negative behavior of a White person.

\section{General Discussion}

We began this research by proposing that the tendency for people to make individual-to-group generalizations primarily from an outgroup member's negative behavior is one factor that may hinder the development of positive intergroup relations. We argued that the generalization process was a result of observing events that prime aspects of the perceiver's belief system. The findings of these three studies tend to support this proposition. First, the findings of Studies 1 and 3 show that observing or hearing about a Black person's negative actions made corresponding group level stereotypes salient. Second, the behavioral findings of Study 1 and Study 2 show that observing a Black person's negative behavior resulted in the desire to avoid contact or minimize interactions with a subsequently encountered Black person. Third, the affective findings of Study 3 indicate that a single negative event involving a Black person led participants to express feelings of ingroup favoritism. Participants in this study also felt as though the power difference between Blacks and Whites in society was smaller after hearing about a Black person's negative behavior. Thus, only when a Black target enacted a negative behavior would participants use the most recently encountered Black person as the relevant category exemplar in making group level judgments.

The irony of the avoidance findings in Study 1 and Study 2 should be noted. If it is a Black person who behaves negatively, Whites will avoid or minimize subsequent interpersonal encounters with Blacks. If a White person behaves in the same way, Whites may still shun Blacks, at least in very fleeting encounters such as that in Study 1. The conditions under which such social slights are recognized by both Blacks and Whites and the possible consequences of such recognition are particularly important to examine in subsequent research.

The attitudinal findings of Study 3 demonstrate the effects of simply hearing about the negative behavior of a single Black man. Whereas all participants recognized the racially based power differential in favor of Whites in contemporary American society, participants in the Black assailant condition saw this differential as much smaller.

The current findings can be seen as extending previous research examining aversive racism (Dovidio \& Gaertner, 1981, 1983; Gaertner \& Dovidio, 1986) and racial ambivalence (Katz. \& Hass, 1988). Dovidio and Gaertner found that under normal circumstances Whites are unwilling to exhibit behavior toward or express attitudes about Blacks that could be interpreted as prejudiced. Dovidio and Gaertner argued that such findings are a result of White Americans' desire to exclude actions from their behavioral repertoire that would contradict their egalitarian values. Our findings indicate that observing a single Black person's negative behavior will enhance the likelihood of Whites exhibiting discriminatory behavior.

Macrae, Bodenhausen, Milne, and Jetten (1994) have found that when perceivers actively attempt to inhibit stereotypic thoughts, these thoughts are likely to resurface and, eventually, have more influence on social judgments than if they had never been suppressed. Suppression is thought to be a function of both controlled and automatic processes. The controlled process involves the perceiver attempting to replace unwanted material with distractor information, whereas the automatic process entails the scanning of conscious awareness in an attempt to identify any unwanted information and replace it with distractor information. Such processes may account for the finding in Study 3 that participants who claimed not to have heard the conversation about a Black assailant nevertheless perceived Blacks as more antagonistic, $M=5.18$, than did those who stated that they had heard it, $M=4.17$. A similar pattern was found for participants' perceptions of Whites as antagonistic in the White assailant condition, with those who claimed not to have heard the conversation perceiving Whites as more antagonistic, $M=5.19$, than did those who claimed to have heard it, $M=3.57$. Because it is generally considered socially unacceptable to eavesdrop on people's conversations, participants may have attempted to replace what they were hearing with other material. Attempting to suppress the conversation may have resulted in the more extreme judgments. Although such findings are in line with those of Macrae et al. (1994), future research should attempt to replicate the current findings with the appropriate controls.

\section{Limitations}

One problem with the current set of studies is that positive stereotypic behaviors were not examined. This problem manifests itself most clearly in Study 1, where the confederate's helping behavior, although positive, was not stereotype related. Although we do not believe that observing a positive stereotyperelated action would have resulted in avoidance, it should have at least activated that aspect of the group stereotype associated with the behavior. The behavior potentially may also have made salient other, related aspects of the group stereotype and influenced general attitudes. Bodenhausen, Schwartz, Bless, and Wanke (1995) recently found that participants who were asked to think about a successful Black exemplar were more likely than those asked to think about a White exemplar to say that discrimination was still a problem for Black Americans. Although these findings were mediated by the perceived typicality of the target, they indicate that a positive category exemplar may influence group level attitudes.

\section{Implications}

Researchers who have examined the relationship between intergroup contact and prejudice reduction have typically focused 
primarily on elements within the contact setting that would benefit individual and intergroup perceptions. For example, Brewer and Miller ( 1984) proposed that positive intergroup and interpersonal relationships would result from people being perceived as individuals as opposed to members of a particular social category. Although we agree that such an outcome is possible, the present findings indicate the difficulty in achieving it. Because people will observe or hear about the negative actions of outgroup members both within and outside the contact setting, the willingness to rely on individual characteristics, as opposed to perceived group characteristics, in making social judgments may be undermined by factors that are difficult for those in the contact setting to control. This may be most likely when the observed actions confirm preexisting attitudes toward the group.

The current findings may also be seen as indicating how intergroup attitudes are influenced by participants making groupserving attributions. Previous research has shown that people tend to attribute the negative actions of outgroup members to dispositional rather than situational factors, whereas similar actions by ingroup members are more often attributed to situational factors (Hewstone, Jaspars, \& Lalljee, 1982; Pettigrew, 1979). The behavior and perceptions of participants in our studies may be seen as outcomes of just such a process. It may be that participants were attributing the Black actor's negative behavior to stable dispositional traits and then generalizing these traits to all Blacks. Potentially, such a process would result in more negative perceptions of Blacks and in a desire to minimize contact with other Blacks. Thus, the current research emphasizes the need to examine whether causal attributions will mediate people's reactions to the behavior of outgroup and ingroup members.

Our findings also suggest that individual-to-group generalization has the potential to initiate a destructive cycle of intergroup interactions. Such a cycle may be initiated when Whites observe the negative, stereotype-related behavior of a Black person and consequently minimize intergroup contact and perceive Blacks more negatively. In turn, Blacks may interpret the behavior of Whites as discriminatory and choose to minimize contact with Whites. This cycle may have major social consequences. Steele (1992) has posited that one reason that minority group members come to "disidentify" with various environments is that they believe members of the majority group fail to distinguish between minority group members and use the actions of a few minority group members as a gauge for subsequently encountered minority group members. The current findings suggest that such a process is all too likely to occur.

\section{References}

Acorn, D. A., Hamilton, D. L., \& Sherman, S. J. (1988). Generalization of biased perceptions of groups based on illusory correlations. Social Cognition, 6, 345-372.

Bodenhausen, G. V., Schwartz, N., Bless, H., \& Wanke, M. (1995). Effects of atypical exemplars on racial beliefs: Enlightened racism or generalized appraisals? Journal of Experimental Social Psychology, $31,48-63$.

Borgida, E., \& Nisbett, R. E. ( 1977). The differential impact of abstract vs. concrete information on decisions. Journal of Applied Social Psychology, 7, 258-271.
Brewer, M. B. (1979). In-group bias in the minimal intergroup situation: A cognitive-motivational analysis. Psychological Bulletin, 86, 307-324.

Brewer, M. B., \& Miller, N. (1984). Beyond the contact hypothesis: Theoretical perspectives on desegregation. In N. Miller \& M. B. Brewer (Eds.), Groups in contact: The psychology of desegregation (pp. 281302). Orlando, FL: Academic Press.

Campbell, D. T., Kruskal, W. H., \& Wallace, W. P. (1966). Seating aggregation as an index of attitude. Sociometry, 29, 1-15.

Clark, M. S., \& Isen, A. M. (1982). Toward understanding the relationship between feeling states and social behavior. In A. H. Hastorf \& A. M. Isen (Eds.), Cognitive social psychology (pp. 73-108). New York: Elsevier/North Holland.

Crosby, F., Bromley, S., \& Saxe, L. (1980). Recent unobtrusive studies of Black and White discrimination and prejudice: A literature review. Psychological Bulletin, 87, 546-563.

Devine, P. G. ( 1989). Stereotypes and prejudice: Their automatic and controlled components. Journal of Personality and Social Psychology, 56, 5-18.

Dovidio, J. F., Evans, N., \& Tyler, R. B. ( 1986). Racial stereotypes: The contents of their cognitive representations. Journal of Experimental Social Psychology, 22, 22-37.

Dovidio, J. F., \& Gaertner, S. L. (1981). The effects of race, status, and ability on helping behavior. Social Psychology Quarterly, 44, 192203.

Dovidio, J. F., \& Gaertner, S. L. (1983). Race, normative structure, and helping-seeking. In B. M. DePaulo, A. Nadler, \& J. D. Fisher (Eds.), New directions in helping: Vol. 2, Help-seeking (pp. 285-302). New York: Academic Press.

Duncan, B. L. (1976). Differential social perception and attribution of intergroup violence: Testing the lower limits of stereotyping Blacks. Journal of Personality and Social Psychology, 34, 590-598.

Fazio, R. H., Jackson, J. R., Dunton, B. C., \& Williams, C. J. (1995). Variability in automatic activation as an unobtrusive measure of racial attitudes: A bona fide pipeline? Journal of Personality and Social Psychology, 69, 1013-1027.

Feldman, J. M., Camburn, A., \& Gatti, G. M. (1986). Shared distinctiveness as a source of illusory correlation in performance appraisal. Organizational Behavior and Human Decision Processes, 37, 34-59.

Gaertner, S. L., \& Dovidio, J. F. (1986). The aversive form of racism. In J. F. Dovidio \& S. L. Gaertner (Eds.), Prejudice, discrimination, and racism (pp. 61-89). Orlando, FL: Academic Press.

Gaertner, S. L., \& McLaughlin, J. P. (1983). Racial stereotypes: Associations and ascriptions of positive and negative characteristics. Social Psychology Quarterly, 46, 23-30.

Gurin, P. (1985). Women's gender consciousness. Public Opinion Quarterly, 49, 143-163.

Gurin, P., \& Townsend, A. (1986). Properties of gender identity and their implications for gender consciousness. British Journal of Social Psychology, 25, 139-148.

Hamill, R., Wilson, T., \& Nisbett, R. E. (1980). Insensitivity to sample bias: Generalizing from atypical cases. Journal of Personality and Social Psychology, 39, 578-589.

Hamilton, D. L., Dugan, P. M., \& Trolier, T. K. (1985). The formation of stereotypic beliefs: Further evidence for distinctiveness-based illusory correlations. Journal of Personality and Social Psychology, 48, 5-17.

Hamilton, D. L., \& Gifford, R. K. ( 1976). Illusory correlation in interpersonal perception: A cognitive basis of stereotypic judgments. Journal of Experimental Social Psychology, 12, 392-407.

Hamilton, D. L., \& Rose, T. L. (1980). Illusory correlation and the maintenance of stereotypic beliefs. Journal of Personality and Social Psychology, 39, 832-845.

Hewstone, M., Jaspars, J., \& Lalljee, M. ( 1982). Social representations, 
social attribution and social identity: The intergroup images of "public" and "comprehensive" schoolboys. European Journal of Social Psychology, 12, 241-269.

Higgins, E. T., Rholes, W. S., \& Jones, C. R. ( 1977). Category accessibility and impression formation. Jeurnal of Experimental Social Psychology, 13, 141-154.

Judd, C. M., Park, B., Ryan, C. S., Brauer, M., \& Kraus, S. (1995). Stereotypes and ethnocentrism: Diverging interethnic perceptions of African American and White American youth. Journal of Personality and Social Psychology, 69, 449-459.

Kalmuss, D., Gurin, P., \& Townsend, A. L. (1981). Feminist and sympathetic feminist consciousness. European Journal of Social Psychology. $11,131-147$.

Katz, I., \& Hass, R. G. (1988). Racial ambivalence and American value conflict: Correlational and priming studies of dual cognitive structures. Journal of Personality and Social Psychology, 55, 893-905.

Katz, I., Wackenhut, J., \& Hass, R. G. (1986). Racial ambivalence, value duality, and behavior. In J. F. Dovidio \& S. L. Gaertner (Eds.), Prejudice, discrimination, and racism (pp. 35-59). Orlando, FL: Academic Press.

Kinder, D. R., \& Sears, D. O. (1981). Prejudice and politics: Symbolic racism versus racial threats to the good life. Journal of Personality and Social Psychology, 40, 414-431.

Lewicki, P. (1985). Nonconscious biasing effects of single instances on subsequent judgments. Journal of Personality and Social Psychology, 48, 563-574.

Linville, P. W., Salovey, P., \& Fischer, G. W. (1986). Stereotyping and perceived distributions of social characteristics: An application to ingroup-outgroup perception. In J. F. Dovidio \& S. L. Gaertner (Eds.), Prejudice, discrimination, and racism (pp. 165-208). Orlando, FL: Academic Press.

Macrae, C. N., Bodenhausen, G. V., Milne, A. B., \& Jetten, J. (1994). Out of mind but back in sight: Stereotypes on the rebound. Journal of Personality and Social Psychology, 67, 808-817.

McConahay, J. B. ( 1982). Self-interest versus racial attitudes as correlates of anti-busing attitudes in Louisville: Is it the buses or the Blacks? Journal of Politics, 44, 692-720.

McConahay, J. B., \& Hough, J. C. (1976). Symbolic racism. Journal of Social Issues, 32, 23-45.

McConnell, R. A., Sherman, S. J., \& Hamilton, D. L. ( 1994). Illusory correlation in the perception of groups: An extension of the distinctiveness-based account. Journal of Personality and Social Psychology, 67, 414-429.

McGuire, W. J., McGuire, C. V., Child, P., \& Fujioka, T. (1978). Salience of ethnicity in the spontaneous self-concept as a function of one's ethnic distinctiveness in the social environment. Journal of Personality and Social Psychology, 36, 511-520.

Meehan, A. M., \& Janik, L. M. (1990). Illusory correlation and the maintenance of sex role stereotypes in children. Sex Roles, 22, 83-95.

Nacoste-Barnes, R., Holt, D., Fender, D., \& Lennon, J. S. (1993). Stigma by policy: Racial ambivalence, affirmative action and the formation of informal groups. Unpublished manuscript.

Nelson, L. J., \& Miller, D. T. (1995). The distinctiveness effect in social categorization: You are what makes you unusual. Psychological Science, 6, 246-249.

Nisbett, R. E., \& Borgida, E. ( 1975). Attribution and the psychology of prediction. Journal of Personality and Social Psychology, 32, 932943.

Nisbett, R. E., Krantz, D. H., Jepson, C., \& Kunda, Z. ( 1983 ). The use of statistical heuristics in everyday intuitive reasoning. Psychological Review, 84, 231-259.

Pettigrew, T. F. (1979). The ultimate attribution error: Extending All- port's cognitive analysis of prejudice. Personality and Social Psychology Bulletin, 5, 461-476.

Quattrone, G. A., \& Jones, E. E. (1980). The perception of variability within in-groups and out-groups: Implications for the law of small numbers. Journal of Personality and Social Psychology, 38, 141-152.

Rosenfield, D., Greenberg, J., Folger, R., \& Borys, R. (1975). Effect of an encounter with a Black panhandler on subsequent helping for Blacks: Tokenism or negative stereotyping. Personality and Social Psychology Bulletin, 8, 664-671.

Rothbart, M., Fulero, S., Jensen, C., Howard, J., \& Birrell, B. (1978). From individual to group impressions: Availability heuristics in stereotype formation. Journal of Experimental Social Psychology, 14, 237-255.

Rothbart, M., \& John, O. P. (1985). Social categorization and behavioral episodes: A cognitive analysis of the effects of intergroup contact. Journal of Social Issues, 41, 81-104.

Rothbart, M., \& Lewis, S. (1988). Inferring category attributes from exemplar attributes: Geometric shapes and social categories. Journal of Personality and Social Psychology. 55, 861-872.

Rothbart, M., \& Park, B. (1986). On the confirmability and disconfirmability of trait concepts. Journal of Personality and Social Psychology, 50, 131-142.

Schachter, S. (1959). The psychology of affiliation. Stanford, CA: Stanford University Press.

Sears, D. O., \& Allen, H. M., Jr. (1984). The trajectory of local desegregation controversies and Whites' opposition to busing. In N. Miller \& M. B. Brewer (Eds.), Groups in contact: The psychology of desegregation (pp. 123-151). Orlando, FL: Academic Press.

Sears, D. O., \& Kinder, D. R. (1985). Whites' opposition to busing: On conceptualizing and operationalizing group conflict. Journal of Personality and Social Psychology, 48, 1141-1147.

Sears, D. O., \& McConahay, J. B. (1973). The politics of violence: The new urban Blacks and the Watts riot. Boston: Houghton Mifflin.

Smith, E. R., \& Lerner, M. (1986). Development of automatism of social judgments. Journal of Personality and Social Psychology, 50, 246-259.

Smith, E. R., \& Zárate, M. A. (1992). Exemplar-based model of social judgment. Psychological Review, 99, 3-21.

Spears, R., Van der Pligt, J., \& Eiser, J. R. ( 1985). Illusory correlation in the perception of group attitudes. Journal of Personality and Social Psychology, 48, 863-875.

Steele, C. (1992, April). Race and the schooling of Black Americans. The Atlantic, pp. 68-78.

Stephan, W. G. ( 1985 ). Intergroup relations. In G. Lindzey \& E. Aronson (Eds.), Handbook of social psychology (pp. 599-658). Reading, MA: Addison-Wesley.

Stephan, W. G., \& Stephan, C. W. (1993). Cognition and affect in stereotyping: Parallel interactive networks. In D. M. Mackie \& D. L. Hamilton (Eds.), Affect, cognition, and stereotyping: Interactive processes in group perception (pp. 111-136). San Diego, CA: Academic Press.

Tversky, A., \& Kahneman, D. (1971). Belief in the law of small numbers. Psychological Bulletin, 76, 105-110.

Weber, R., \& Crocker, J. (1983). Cognitive processes in the revision of stereotypic beliefs. Journal of Personality and Social Psychology, 45. 961-977.

Weitz, R., \& Gordon, L. (1993). Images of Black women among Anglo college students. Sex Roles, 28, 19-34.

Wilder, D. (1984). Intergroup contact: The typical member and the exception to the rule. Journal of Experimental Social Psychology, 20, 177-194.

Received July 12, 1995

Revision received May 13, 1996

Accepted May 13, 1996 